\begin{tabular}{llll}
$\begin{array}{l}\text { Abstract PO-0654 Table 2 Adjusted } \\
\text { sibling birth }\end{array}$ & model estimating next \\
\hline Variable* & HR & $\begin{array}{l}95 \% \text { CI for Exp (B) } \\
\text { Lower }\end{array}$ & Upper \\
& & 0.97 & 1.00 \\
Male & 0.99 & 0.54 & 0.81 \\
$<28$ & 0.66 & 0.66 & 0.82 \\
$28-31$ & 0.74 & 0.90 & 0.95 \\
$32-37$ & 0.93 & 1.17 & 1.23 \\
$>42$ & 1.20 & 0.76 & 0.79 \\
\hline Miscarriages & 0.77 & &
\end{tabular}

(1.3\%) and miscarriage data for 2964 (1.3\%); 225650 children remained in analyses.

We utilised Cox regression for proportional hazards to analyse the effect of GA and history of miscarriages on sibling birth. Results A low GA at birth delayed subsequent sibling birth. The effect remained unchanged after introducing miscarriages in the model.

*Numbers indicate completed gestational weeks. HR, Hazard Ratio (term group, females and no miscarriages as a referent). Conclusions Prematurity postponed subsequent sibling birth. Accounting for obstetric history left this effect unchanged.

\section{PO-0655 THE EFFICACY OF SNAPPE-II IN PREDICTING MORBIDITY AND MORTALITY IN EXTREMELY LOW BIRTH WEIGHT INFANTS}

S Ucar, M Varma, MI Ethemoglu, NK Acar. Department of Pediatrics, OSM Middle East Hospital, Sanliurfa, Turkey

\subsection{6/archdischild-2014-307384.1296}

Background and aims Various scoring system are used to predict morbidity and mortality. Among these the "Score for Neonatal Acute Physiology-Perinatal Extension-II" (SNAPPE-II) predicts the risk of mortality based on data collected within the first day of the newborn. We aimed to determine the efficacy of SNAPPE-II in predicting mortality in extremely low birth weight infants (ELBW). We also assessed its efficacy in predicting the potential causes of neonatal morbidity.

Methods Data from infants admitted between June 2012 and June 2013 to the neonatal intensive care unit with a birth weight less than $1500 \mathrm{gr}$ were collected in a retrospective manner. SNAPPE-II score was calculated for the first $24 \mathrm{~h}$ of each infant. The efficacy of SNAPPE-II score in predicting intra ventricular haemorrhage (IVH), necrotizing enterocolitis (NEC) and bronchopulmonary dysplasia (BPD) as well as mortality was evaluated.

Results A total of 182 infants (98 males and 84 females) were enrolled in the study. Mean birth weight was 1,134 $\pm 264 \mathrm{~g}$. The most notable scores documented for SNAPPE-II were 33 for mortality (sensitivity $86.6 \%$, specificity 76,4\%), 23 for IVH (sensitivity $88.2 \%$, specificity 64.6\%), 39 for NEC (sensitivity $78.7 \%$,specificity $72.6 \%$ ) and 36 for BPD (sensitivity $87,8 \%$, specificity $69,4 \%)$. Infants with a high SNAPPE-II score had significantly higher rates of IVH $(p<0,001)$, NEC $(p=0,014)$ and BPD ( $\mathrm{p}=0,003)$.

Conclusions We found that a high score of SNAPPE-II in premature infants was independently associated with neonatal mortality as well as with factors know to be associated with neonatal morbidity, such as IVH, NEC and BPD.

\section{P0-0656 THE EVALUATION OF 263 NEWBORNS WITH MENINGOMYELOCELE: FIVE YEARS OF EXPERIENCE}

'S Ucar, ${ }^{1} \mathrm{M}$ Varma, ${ }^{2} \mathrm{M}$ Gok, ${ }^{2} \mathrm{~B}$ Celik, ${ }^{3} \mathrm{~A}$ Yesilay. ${ }^{1}$ Department of Pediatrics, OSM Middle East Hospital, Sanlurfa, Turkey; ${ }^{2}$ Department of Neurosurgery, OSM Middle East Hospital, Sanlurfa, Turkey; ${ }^{3}$ Department of Anesthesiology, OSM Middle East Hospital, Sanlurfa, Turkey

\subsection{6/archdischild-2014-307384.1297}

Background and objectives Meningomyelocele (MMC) is a congenital malformation characterised by the herniation of a part of the spinal cord with surrounding meningeal structures as a sac through an open spinal canal. In this study we aimed to evaluate the demographic and clinical features of MMC cases followed in our neonatal intensive care unit, to investigate the accompanying congenital malformations and the effects of operation timing on mortality and morbidity.

Methods Patients between January 2009 and January 2014 were evaluated retrospectively. The patients were analysed according demographic features, additional malformations, operation timing and the ratio of an additionally ventriculoperitoneal shunt placement because of concomitant hydrocephaly. The effects of operation timing on mortality, complications and the lenght of hospital stay were investigated.

Results 263 patients were included in this study 152 male (57.8\%), 111 female (42.2\%). The ratio of prenatal diagnosis was $77.2 \%$ and the paternal consanguinity ratio was $51.3 \%$. Ventriculoperitoneal shunting was performed to $72.6 \%$ of the patients after the MMC surgery. The lenght of hospital stay, total period of antibiotic use and the mortality ratio were significantly lower in the cases among whom the operation time was less than three days ( $\mathrm{p}$ values are $0.006,0.014,0.004$ respectively).

Conclusions The ratio of births with MMC is higher in our city when compared with another countries and the high ratio of paternal consanguinity imight be responsible for this difference and. The mortality and rate of complications can be decreased by early performing of MMC surgery.

\section{PO-0657 ASSESSMENT OF EXTREMELY LOW BIRTH WEIGHT INFANTS IN A NEONATAL INTENSIVE CARE UNIT OF A TERTIARY REFERRAL HOSPITAL}

S Ucar, IH Baysal, M Varma, S Gunes. Department of Pediatrics, OSM Middle East Hospital, Sanliurfa, Turkey

\subsection{6/archdischild-2014-307384.1298}

Background and aims Due to severe postnatal complications, the morbidity and mortality rate of extremely low birth weight (ELBW) premature infants remains significantly high. We aimed to assess the morbidity and mortality rates as well as the demographic characteristics of ELBW infants admitted to a neonatal intensive care unit (NICU).

Methods ELBW infants admitted to the NICU between March 2010 and 2013 were included in the current study. Demographic characteristics, the type of surfactant and the need for a repeat dose, the need for mechanical ventilation and etiologic factors associated with morbidity and mortality were retrospectively assessed.

Results A total of 134 infants were enrolled in the study. Mean birth weight was $836 \pm 155 \mathrm{~g}$ and mean gestational week was $26.4 \pm 1.7$ weeks. While all the infants received surfactants, $41.8 \%$ were treated with beractant, and $58.2 \%$ with proctant alfa. Overall mortality rate was $59.7 \%$. The need for repeated 